\title{
Presencia de Buenos Aires en "La Muerte y la Brúlula" de Jorge Luis Borges
}

$S_{y}$ pueden advertir dos planos en "La muerte y la brújula", uno real propósito, cediendo a una actitud estética particular suya que podríamos llamar barroca.

Si el lector logra superponer los dos planos obtendrá una estampa nítida, casi realista, como esas postales vistas a través de un aparato estereoscópico; pero si no alcanzamos la perspectiva tridimensional, es decir, si se nos escapa uno de los dos planos, el valor del cuento no varía. Su fuerza y su belleza no dependen de ese virtuosismo. La dualidad de planos es sólo un elemento en la armadura total del relato.

"La muerte y la brújula" es una ficción. El plano real está escamoteado, o al menos estilizado de tal forma que la atmósfera ficticia se imponga. Lo que llamamos el plano real es el escenario del cuento; en este caso, la ciudad de Buenos Aires.* El propósito de esta nota es señalar la presencia de Buenos Aires; ajustar las lentes hasta que la ciudad ficticia se identifique con la ciudad real.

Claro que el lector porteño está en situación de ventaja en este

* Borges explicó así su deliberado escamoteo de localismos en este cuento: "Durante muchos años, en libros ahora felizmente olvidados, traté de redactar el sabor, la esencia de los barrios extremos de Buenos Aires; naturalmente abundé en palabras locales, no prescindí de palabras como cuchilleros, milonga, tapia y otras, y escribí así aquellos olvidables y olvidados libros; luego, hará un año, escribí una historia que se llama La muerte y la brújula que es una suerte de pesadilla, una pesadilla en que figuran elementos de Buenos Aires deformados por el horror de la pesadilla; pienso allí en el Paseo Colón y lo llamo Rue de Toulon, pienso en las quintas de Adrogué y las llamo Tiste-le Roy; publicada esa historia. mis amigos me dijeron que al fin habian encontrado en lo que yo escribía el sabor de las afueras de Buenos Aires. Precisamente porque no me había propuesto encontrar ese sabor, porque me había abandonado al sueño; pude lograr, al cabo de tantos años, lo que antes busqué en vano". ("El escritor argentino y la tradición", en Discusión, vol, $6^{\circ}$ de Obras completas, Buenos Aires, Emecé, 1957, pág. 157). 
punto. Puede captar casi instantáneamente las alusiones, ubicarse en el mapa de su ciudad y seguir las pistas insinuadas. Pero, según lo veremos en seguida, Borges ha preparado su acertijo de tal suerte que hasta los lectores porteños se desorienten y penetren de buena fe en la atmósfera de pura invención.

En primer lugar, recordemos que "La muerte y la brújula" es la narración de cuatro crímenes que ocurren en los cuatro puntos cardinales. El asesino aprovecha la mentalidad teorizante de su adversario, el investigador Lönnrot, para atraerlo, mediante una ingeniosa charada geométrica, al vértice vacío del rombo, al Sur de la brújula, donde tendrá lugar el cuarto crimen. La cuarta víctima, obviamente, será el mismo Lönnrot.

Asi, en abstracto, no importa dónde se desarrolle; no importa el tiempo. Por eso la historia no pierde su fuerza aunque muchos lectores no lleguen a identificar la ciudad. Sin embargo, Borges ha dibujado su. ciudad ideal calcando el plano de Buenos Aires y poniendo nombres ficticios a lugares reales de su ciudad.

La primera pista se nos aparece en el "Hotel du Nord", "ese alto prisma que domina el estuario cuyas aguas tienen el color del desierto" ( 143$) \cdot(* *)$.

El nombre del hotel cumple una función en el cuento: la de indicarnos que el primer crimen se cometió en el Norte. Pero no es éste el Norte abstracto; no se trata del mero Norte de la brújula, aunque para el caso resulte lo mismo. Este hotel domina un estuario. Podría ser en Londres, o en Manhattan, ciudades edificadas en la desembocadura de anchos ríos. Sólo que las aguas de este estuatio tienen "el color del desierto", metáfora que ya singulariza al Plata, al menos para el habitante inmediato, familiarizado con el color pardo de nuestro río mayor. (De paso, "color del desierto" despierta en el lector argentino otras imágenes similares con que se alude al Plata: "el río inmóvil", "prolongación de la pampa", "pampa de agua", "río color de león").

Más abajo encontramos otra pista, algo menos velada que la primera, pero tan fugaz, que corremos el riesgo de pasarla por alto. "Hacia el amanecer, uno de los gendarmes que vigilan a caballo esas soledades vió en el umbral de una antigua pinturería un hombre emponchado, yaciente" (I47).

(**) Los números de página que siguen a todas las citas corresponden al volumen Ficciones de las obras completas de Borges (Emecé, Buenos Aires, 1958. 2a. edición) que incluye "El jardín de los senderos que se bifurcan" (1941) y Artificios (1944). "La muerte y la brújula" pertenece al segundo de estos libros. 
Está emboscada, y estilísticamente es impecable. "Yaciente" nos cautiva por su posición final y porque con ella acabamos de descubrir el segundo cadáver, y casi se nos escapa el otro adjetivo, "emponchado", hasta que se nos ocurre pensar que dificilmente tropezaríamos con un cadáver emponchado en Londres o en New York.

Este segundo crimen ha ocurrido en el Oeste y Borges nos da una vaga descripción del Oeste porteño: callejones y bartizales donde "ya importaban poco las casas y mucho un horno de ladrillos, o un álamo" (147). Pero aún va más allá: esta vez nos refiere a una fuente literaria, válida sólo para los lectores de Borges. Él escribió un cuento, "El hombre de la esquina rosada" (en Historia universal de la infamia, 1935) y un poema, "Calle con almacén rosado" (en Lima de enfrente, r925) con motivos de arrabal porteño, y he aquí que nos dice en "La muerte y la brújula": "Legaron a su pobre destino: un callejón final de tapias rosadas que parecían reflejar de algún modo la desaforada puesta de sol" (147), dándonos así una indicación más de que esta historia tuvo lugar en su ciudad.

El tercer crimen, esta vez simulado, ocurrió en "Liverpool House", taberna de la Rue de Toulon, "esa calle salobre en la que conviven el cosmorama y la lechería, el burdel y los vendedores de biblias" ( 148 ).

Esta Rue de Toulon no es otra que el Paseo de Julio, (lo dice el mismo Borges en otro lugar que será comentado oportunamente), de modo que no hay dudas sobre su identidad. A pesar de eso, Borges nos $\mathrm{da}$ otros datos para que nos orientemos en este plano ideal de Buenos Aires y formemos mentalmente el triángulo previsto por Red Scharlach, el pistolero razonador. Ahora estamos en el extremo oriental de la ciudad.

"Rumbo a la dársena inmediata - sigue el cuento-, de agua rectangular, los tres subieron al cupé y desaparecieron. Ya en el estribo del cupé, el último arlequín garabateó una figura obscena y una sentencia en las pizarras de la recova" (I49).

La recova, palabra porteña, si las hay, con resonancias de la gran aldea, es por antonomasia, el Paseo de Julio, o su continuación, el Paseo Colón, igualmente "salobre". En aquel extremo de la ciudad se hallan las dársenas en cuyas aguas se supone que fue arrojado el tercer cadáver.

Durante el mes siguiente hubo un revuelo periodístico. Se comentaba en diversos tonos la falta de acción policial. Los periódicos judíos protestaban alarmados los repetidos asesinatos que tenían un notorio 
sentido antisemita. Por el contrario, los diarios de extrema derecha exigían a los asesinos mayor eficacia en su pogrom. En uno de esos diarios figura un cronista llamado Ernst Palast, broma escasamente disimulada de Borges a Ernesto Palacio, escritor de inclinaciones nacionalistas (uno de los fundadores de la revista Martín Fierro, de paso), en quien sería verosímil este antisemitismo que en el cuento se adscribe al ficticio $\mathrm{Pa}$ last.

Más adelante, y ya en el acto final, Lönnrot toma un tren de los "Ferrocarriles Australes", con lo que el autor nos conduce al cuarto punto cardinal de su geografía fantástica. Estos ferrocarriles australes aluden al Ferrocarril Sud, nombre tradicional de la línea que partiendo de Buenos Aires, une esa larga cadena de suburbios, en uno de los cuales encontratá su fin el detective. Por si esto fuera poco, dice Borges en más explícita referencia a lugares reales: "Al sur de la ciudad de mi cuento fluye un ciego riachuelo de aguas barrosas, infamado de curtiembres y de basuras. Del otro lado hay un suburbio fabril donde, al amparo de un caudillo barcelonés, medran los pistoleros" (I52).

Y bien: ese "riachuelo" es el Riachuelo y el "suburbio fabril", Avellaneda. El "caudillo barcelonés" ( $y$ aquí hay que reconocer que los nombres reales cayeron de medida) es, precisamente, Alberto Barceló, hombre temido de muchos, venerado por otros, cuyo nombre representa toda una época en la historia política y policial de Buenos Aires.

Estas son las pistas detrás de las cuales se esconde el escenario real de "La muerte y la brújula", no para universalizarlo quitándole las connotaciones reales, porque según Borges ni el espacio ni el tiempo tienen importancia alguna en este relato, (***) sino para crear un enigma adicional en el que pueda participar el lector. Con todo, aún arma una trampa más. En el prólogo a Artificios, que incluye "La muerte y la brújula" en la edición aquí utilizada, se lee: "La primera [pieza] pese a los nombres alemanes y escandinavos ocurre en un Buenos Aires de sueños" (II5). A renglón seguido, y como para ponernos en el buen sendero, nos da un par de referencia: "Ia torcida Rue de Toulon es el Paseo de Julio" (II5), pero de inmediato borra las huellas al añadir: "Triste-le-Roy, [es] el hotel donde Herbert Ashe recibió, y tal vez no leyó el tomo undécimo de una enciclopedia ilusoria" (Ir5).

(***) "Ya redactada esa ficción, [se refiere a "La muerte y la brújula"] he pensado en la conveniencia de amplificar el tiempo y el espacio que abarca: la venganza podría ser heredada; los plazos podrían computarse por años, tal vez por siglos; la primera letra del nombre podría articularse en Islandia; la segunda, en México; la tercera en el Indostán". (Prólogo a Artificios, 1944). 
En estas líneas Borges está seleccionando los jugadores para este entretenimiento exclusivo. El que no esté en el secreto no podrá seguir el juego aunque conozca las reglas (v. gr.: la Rue de Toulon es el Paseo de Julio) porque Herbert Ashe y esa "enciclopedia ilusoria" no sig. nificarán nada para él y perderá interés. En cambio el lector asiduo de Borges recordará que "El jardín de los senderos que se bifurcan" ... (I94I) se inicia con aquella maravillosa fantasía titulada "Tlön, Uqbar, Orbis Tertius" y que allí Herbert Ashe, "ingeniero de los Ferrocarriles del Sur", aparece alojado en un hotel de Adrogué, "entre las efusivas madreselvas y en el fondo ilusorio de los espejos" (I7).

Queen's University,

Kingston, Canadá.

OCtAvio CORvalán 
